\title{
sciendo
}

\section{The mediation role of knowledge management between academic management and business education}

\author{
Constantin BRATIANU \\ Bucharest University of Economic Studies, Bucharest, Romania \\ constantin.bratianu@gmail.com \\ Dan Florin STANESCU \\ National University of Political studies and Public Administration, Bucharest, Romania \\ dan.stanescu@comunicare.ro \\ Rares MOCANU \\ National University of Political studies and Public Administration, Bucharest, Romania \\ rares.mocanu@facultateademanagement.ro
}

\begin{abstract}
The goal of this study is to examine knowledge management's function as a mediator between academic management and business education. Knowledge management evolved in the last decades as an important component of the organizational management that focuses on intangible resources. In the knowledge economy, knowledge became a strategic resource and it needs a different type of management because it has different economic characteristics by comparison with tangible resources which are represented by physical objects. Knowledge management becomes dominant in the knowledge-intensive organizations, like universities, research centers, consulting companies, and those organizations where knowledge density and knowledge processes intensity determine the organizational performance.

From this perspective, it is interesting to analyze the role played by knowledge management in mediating the complex correlation between academic management and business education. Academic management is considered an independent variable and business education the outcome of the whole management of the teaching and learning processes. Knowledge management is the mediator of the whole process. The present research is based on qualitative and quantitative analyses. Qualitative investigation consist in a critical analysis of the literature, and quantitative research is a survey based on a questionnaire addressed to students and professors involved in business education from two Romanian universities. Statistical processing was done with SPSS version 26.0 and the macro PROCESS version 3.5. The findings back up the basic hypothesis and support the research model.
\end{abstract}

Keywords: knowledge management, academic management, business education, learning, competencies.

\section{Introduction}

Business education is designed by the business schools, but it is driven by the needs of the business environment and its dynamics (Drucker, 2008; Martin, 2009; Mintzberg, 2004). In the last decades, changes in the business environment became faster and many of them were unpredictable. "Our current environment of accelerated uncertainty and change is not going to blow over and settle down" (Horney et al., 2010, p. 33). We enter the VUCA world, i.e. a world characterized by volatility (V) - the dynamics of change, uncertainty (U) - the lack of predictability, complexity (C) - nonlinearity and chaos, and ambiguity (A) - the haziness of reality and the mixed meanings of environmental changes. The US Army War College coined the term VUCA to capture the emerging dynamics of the economic, business, and political environments in strategic analysis (Horney et al., 2010). The COVID-19 global crisis can be a

DOI: $10.2478 /$ picbe-2021-0010

(C) 2021 C. Bratianu, D. F. Stanescu, R. Mocanu, published by Sciendo.

This work is licensed under the Creative Commons Attribution 4.0 License. 
good example of such a VUCA world in which the initial epidemic started in Wuhan, China, in December 2019 transformed very fast into a pandemic that generated complex economic, business, social, cultural, and educational crises (Bratianu, 2020; Surico \& Galeatti, 2020; Zakaria, 2020).

These variations have an impact on the labor markets (OECD, 2005; OECD, 2018). This is a significant challenge for business university programs since they prepare students for "jobs that have yet to be created, technology that have yet to be conceived, and challenges that have yet to be foreseen. Seizing opportunities and finding solutions will be a shared duty." (OECD, 2005, p. 2). The challenge stems from the curriculum's design, which is founded on linear thinking and the assumption of a latent environment. Moreover, the regulations imposed by the quality evaluation and institutional accreditation national agency ARACIS lead to standardization and rigidity in changing university programs and the structure of curricula for business students.

Mintzberg (2004) claims based on a thorough examination of these programs, that MBA programs in the United States and Canada "teach the wrong people in the wrong methods and with the wrong results." (p. 6). These programs should be adaptable, tailored to new job market demands, and based on strategic and probabilistic thinking, keeping in mind the dynamism of the corporate environment (Bratianu \& Vasilache, 2009; Kahneman, 2011; Taleb, 2012). Knowledge management can play an important role in re-designing business curricula and in creating a new paradigm of the integrated process of teaching and learning aiming at developing skills and competences for students (Bratianu \& Vatamanescu, 2017; Eizaguirre et al., 2019). Also, customer knowledge management becomes significant because of the changes observed in the customers' needs and as a result in their behavior (Mocanu, 2020). Business students should understand these driving forces of change and learn how to develop their strategic thinking, decision-making, creativity driven innovation, brand management and customer knowledge management. Thus, knowledge management can have a pivotal role in designing the curriculum and the learning environment of the business students being an integral component of the academic management. While the academic management is focusing more on the organizing the learning process of the business students, the knowledge management focuses on the content of the process and on developing the needed generic competences for a changeable and uncertain job market for business and economics. The research question for the present paper is the following:

RQ: How important is the mediating role of knowledge management between academic management and business education?

The structure of the paper is designed as follows: after this introductory part is a critical literature review, and then the research model and the methods used in the present research. It follows a section of results and discussions, and then some concluding remarks. Finally, the paper contains the list with references used.

\section{Literature review}

Academic management is the driving force of the university governance and it is responsible for the organizational performance (Bratianu \& Pinzaru, 2015; Shatock, 2006). Academic management through different decisional procedures, which vary from university to university, design and approve the curricula for undergraduate and graduate students for the whole spectrum of disciplines and study domains. Thus, business education curriculum is design by professors in 
concordance with the requirements imposed by legislation and some accreditation agencies, and approved by the university senate. Curriculum contains all the compulsory and optional disciples students should have in order to get a university degree. However, conceived only from the academic perspective, curriculum lacks those elements specific for the business environment students should have (Gherardi et al., 1998).

Against this backdrop, recent studies show how the curriculum can be contextualized by creating a learning environment (Tsang \& Tsui, 2017; Tsui \& Dragicevic, 2018). The model of curriculum co-creation contains three layers: professors' layer, students' layer, and graduates and practitioners' layer. Professors design the framework of the curriculum and its basic structures, students develop scenarios and co-create extensions of the basic curriculum, and graduates and practitioners bring in the specific features of the changeable business environment. "The proposed approach signifies a shift in perspective on universities from places where knowledge learned outside the classroom is reported to students to one where students themselves become researchers, co-creators of knowledge, and co-creators of curriculum" (Tsui \& Dragicevic, 2018, p. 855). These new ideas come from the knowledge management philosophy of using creatively the intangible resources of any organization. Knowledge management becomes this way a mediator factor between academic management and business education. Within knowledge management, knowledge sharing plays an important role in enhancing business education (Kurti et al., 2018).

Universities are knowledge-intensive organizations focusing on teaching, learning, and knowledge creation processes. They generate a dominant intellectual capital (Andriessen, 2004; Bratianu, 2014; Ricceri, 2008) or knowledge capital (Garcia-Perez et al., 2020; Lafayette et al., 2019). Teaching is a process of knowledge transfer from the professors to the students and can be performed face-to-face in classrooms, or by using online platforms. The COVID-19 crisis that forced many governments to close schools and universities demonstrated that classical teaching in classrooms can be replaced by online teaching, although results cannot be the same. Teaching implies not only rational knowledge but also emotional and spiritual knowledge. This spectrum of knowledge and its dynamics (Bratianu \& Bejinaru, 2020) cannot be used integrally in online teaching because of the technological interface between professors and students.

Learning is the process of acquiring new knowledge by students. Learning is performed in several sequences which imply lectures delivered by professors, study case debates, literature search and individual studying, and performing some practical applications in laboratories or in the business environment. Traditional learning theories were based implicitly on the assumption that learning is a linear process and knowledge is obtained by a summation process. That is derived from the container metaphor. "Learning, according to an earlier perspective, consists of taking in information from the outside. The mind, according to the more popular constructivist viewpoint, creates the objects it includes. The container metaphor, on the other hand, persists, and this is where the difficulty begins." (Bereiter, 2009, p. 20).

Learning is a complex and a continuous process and it should not be reduced to the formal university framework design based on a linear curriculum. In business education, learning should include the direct experience of the students in a business environment, experience that generates emotional knowledge and stimulates them to think of the specific value system of the business enterprise. "Learning as a holistic adaptive process creates conceptual bridges between life settings such as school and employment, depicting learning as a continuous, lifetime activity." (Kolb, 2015, p. 45). Learning integrates cognition and emotion, which are influencing each other (Damasio, 2012; Friedenberg \& Silverman, 2016). 
Business students should learn not only economic principles and methods for increasing efficiency and profitability, but also for value creation for their community. That leads to develop a sense of responsibility for the future decision-makers in concordance with the agency theory and the leadership principles (Bass \& Reggio, 2006; Daft, 2008). One can see these ideas expressed very clearly in the mission statements of some of the most prestigious graduate schools of business, like Stanford University and Harvard University.

In the OECD Report "Future Education and skill development. 2030 education." it is underlined the necessity of transforming the old style of teaching and learning such that students develop competencies to transform our society and shape our future. "Competence entails more than the acquisition of knowledge and abilities; it also entails the mobilization of knowledge, skills, attitudes, and values in order to meet complicated demands. Future-ready students will need both broad and specialized knowledge" (OECD, 2018, p. 5). Changing the paradigm of knowledge transfer into one focusing on developing skills and competencies is supported by both theoretical and empirical research (Bejinaru, 2018; Le Deist \& Winterton, 2005; Lozano et al., 2017). Based on a critical analysis of several definitions and many interpretations of the concept of "competence", Bratianu, Hadad and Bejinaru (2020) formulate the following working definition: "Competence is defined as a dynamic combination of knowledge, abilities, and attitudes capable of doing a generic activity at a high level of quality in a specific situation. A generic skill is one that is complex enough to produce a synergy between cognitive, emotional, and spiritual knowledge, resulting in higher performance." (p. 5).

Designing business education based on these above ideas cannot be performed by the academic management solely because many new requirements entail the new philosophy of knowledge economy and that is why knowledge management should come into play as a mediator between academic management and business education.

\section{Methodology}

As described in the literature review and addressed in the research question, this study aims to identify the causal effect of academic management (AM) influencing the outcome in business education (BE) through the mediation of knowledge management (KM) as an intervening variable.

The proposed conceptual model is a two pathways system (see Figure 1) from which one pathway is found by tracking the direct effect of academic management (AM) the antecedent variable on business education (BE) the consequent variable. The second pathway is related to the indirect effect of academic management (AM) on business education (BE) through the intervening variable of knowledge management (KM) as a mediator. This conceptual mediation framework is established by the evidence of cause and effect between the predictor AM and the outcome $\mathrm{BE}$ that is unrelated to changes in the KM mediator variable.

The impact of the knowledge management (KM) mediator, perceived as a process that receives contributions from the context of academic management (MA), is reconfigured, allowing the transfer of new knowledge between different components of the educational process. This relationship aligns the quality of educational activities to the external context, which eventually will lead to changes in business education (BE). It is important to interpret this framework as a dynamic process that assumes that once AM exerts its effect on KM, then KM's causal influence on $\mathrm{BE}$ produces variations in $\mathrm{BE}$. 


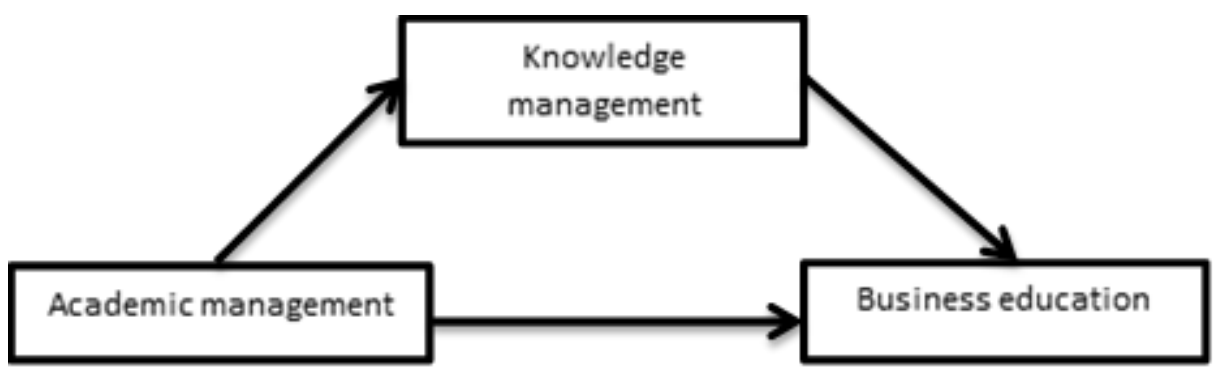

PICBE |

Figure 1. Mediation model

Source: Authors' own research.

To better represent the model framework and the relationships between the constructs it is necessary to deconstruct the RQ stated in the introduction into two functional research questions:

RQ1. What is Academic Management's (AM) direct effect on Business Education (BE)?

RQ2. What are the processes whereby Academic Management (AM) influences Business Education (BE) through Knowledge Management (KM) as a mediator?

Given the above considerations, the present study integrates exploratory and confirmatory analysis used to identify the underlying structure of the data for each construct, followed by the bivariate correlation and regression analysis of the mediation to specify the relationship between the constructs.

To evaluate the mentioned research questions, a questionnaire survey was undertaken with the support of students and lecturers from business management study programs at the University of Economic Studies and the National School of Political Science and Public Administration of Bucharest, Romania. The questionnaire was intended for university instructors, master's and doctorate students as well as students in their last year of bachelor's programs. The questionnaire incorporated the following sections: comprehensive information about the respondents, items, and associated construct scales KM - Knowledge Management; AM Academic Management and BED - Business Environment.

After searching for outlier answers, there remained 206 questionnaires. Participants' ages ranged from 19 to 63 years old $(\mathrm{M}=25.02, \mathrm{SD}=8.72)$. Table 1 indicates the frequency of respondents based on their educational level. A purposive convenience sample strategy was employed to acquire data. The goal of the study was briefly described to the respondents before completion, and informed consent was obtained.

Table 1. Educational level sample frequency

\begin{tabular}{lll}
\hline $\mathbf{n = 2 0 6}$ & Frequency & Percent \\
\hline Bachelor & 96 & 46.6 \\
Master & 82 & 39.8 \\
Doctorate & 13 & 6.3 \\
Professors & 15 & 7.3 \\
\hline
\end{tabular}

Source: Authors' own study.

DOI: 10.2478/picbe-2021-0010, pp. 102-112, ISSN 2558-9652 |

Proceedings of the $15^{\text {th }}$ International Conference on Business Excellence 2021 
Three sets of measures were established in order to get consistent data, with the goal of having a significant representation of the link between each of the proposed model dimensions (AM, KM, BE). The scales' preliminary versions were tested on 112 people. The final version of the questionnaire was selected after a thorough examination of each item's contribution to scaling reliability. As indicated in Table 2, Cronbach's alpha was used to compute the internal consistency coefficients for all of the study model variables. The results exceeded the required value of 0.7 (Bonett \& Wright, 2014; Chen \& Mohamed, 2008), indicating that the variables' dependability was satisfactory. The assessments for all three items were supplied on a 5-point Likert-type scale ( 1 = strongly disagree, $5=$ strongly agree $)$.

Table 2. Reliability statistics

\begin{tabular}{lll}
\hline Scale name & N of items & Cronbach's alpha \\
\hline Academic Management (AM) & 6 & 0.854 \\
Knowledge Management (KM) & 6 & 0.851 \\
Business Education (BE) & 6 & 0.934 \\
\hline
\end{tabular}

Source: Authors' own research.

Academic management (AM) has been determined by combining respondents' ratings of the university's various actions and behaviors, such as "The university's prompt responses to changes in the external environment and business context", respective, "The synergies and collaboration universities with the business environment". The items used for the KM construct were directed on knowledge processes and sharing, i.e. "The facilities and access to extensive international databases of scientific papers supplied to students"; "The intensive share of knowledge and practice sessions" and "Students are encouraged to share knowledge and competence".

The items used for the BE construct were concentrated on knowledge competencies and generic skills such as: "Students benefit from significant and up-to-date academic and practical knowledge about market context and business environment"; "Methods and practices for the development of entrepreneurial and business skills", and "The interrelated body of knowledge for the development of critical and strategic thinking skills".

\section{Results and discussions}

The acquired data were analyzed using SPSS 26.0 software, which included Andrew Hayes' conditional PROCESS macro analysis for SPSS version 3.5. (Hayes, 2012). Finally, to evaluate the significance of the mediation effect, a Sobel test (quantpsy.org/sobel/sobel.html) has been used to assess whether the decrease in the effect of the independent variable after including the mediating variable is significant (Preacher \& Hayes, 2004). The study of the skewness and kurtosis measurements reveals that their values are within the permissible range for the data distribution. Some descriptive statistics are presented in Table 3.

The descriptive statistics for AM, KM and BE give mean scores and standard deviation for measuring the statistical significance and variability of the suggested constructs. The studies clearly indicate that several factors related to academic management processes and educational activity performance (e.g., rapid organizational response to changes in the business environment, cointegration of university curricula to business and workforce requirements, development of professional competencies for students, and better partnerships with the corporate environment) 
are by far the most significant characteristics for the university and its educational performance. $\mathrm{AM}$ has the highest value $(\mathrm{M}=4.02, \mathrm{SD}=.74), \mathrm{KM}$ has the second-highest value $(\mathrm{M}=3.72$, $\mathrm{SD}=.82)$, and $\mathrm{BE}$ has the lowest value $(\mathrm{M}=3.88, \mathrm{SD}=.90)$. The examination of skewness and kurtosis measurements (Table 3) revealed that the observed degree of asymmetry of the data set was within the acceptable interval for the normal data distribution.

Table 3. Expository statistics

\begin{tabular}{llllll}
\hline & N & M & SD & Skewness & Kurtos is \\
\hline Academic Management (AM) & 206 & 4.02 & 0.74 & -0.759 & -0.09 \\
Knowledge Management (KM) & 206 & 3.72 & 0.82 & -0.466 & -0.267 \\
Business Education (BE) & 206 & 3.88 & 0.9 & -0.693 & -0.138 \\
\hline & & & \multicolumn{3}{c}{ Source: Authors' own research. }
\end{tabular}

Correlation analysis on the basis of the proposed model was employed to envisage the relationship between the constructs. The Pearson product-moment correlation method has been used to demonstrate that all five constructs are positively related.

The examination of the data in Figure 2 reveals a significant correlation ( $r=.770)$ between Academic Management (AM) and Knowledge Management (KM), indicating that the initial step of mediation is essential for the role of Knowledge Management (KM). Another important positive relationship between Knowledge Management (KM) and Business Education (BE) is highlighted by the strong correlation value $(\mathrm{r}=.770)$, indicating that the second phase of the mediation effect is significant. The provided data demonstrate that academic management AM and knowledge management KM are influential integrators for a university.

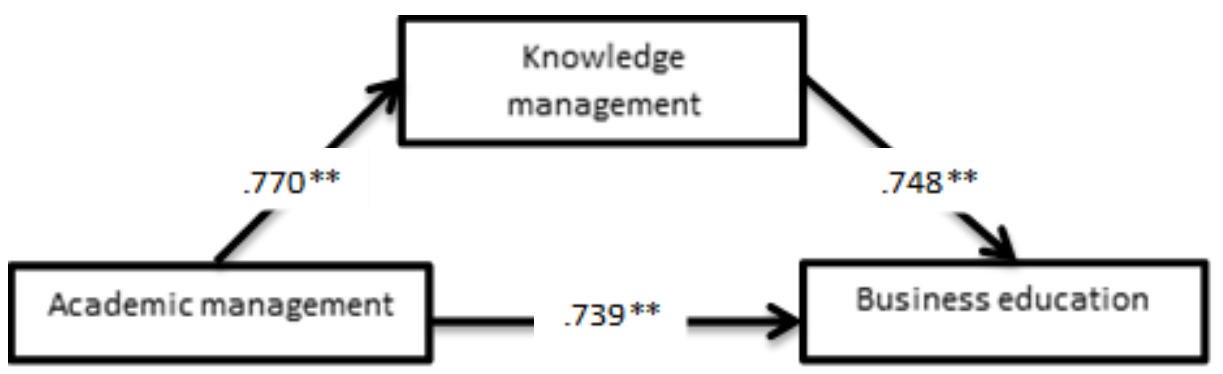

Figure 2. Correlations analysis

Source: Authors' own research.

More details concerning the correlations among variables are presented in Table 4.

Table 4. Bivariate correlation among variables

\begin{tabular}{llll}
\hline & \multicolumn{2}{c}{$\mathbf{1}$} \\
\hline Academic Management & Pearson Correl. & \multicolumn{2}{l}{} \\
& Sig. & \multicolumn{2}{l}{} \\
Knowledge Management & Pearson Correl. & $.770^{* *}$ \\
& Sig. & 0 & \\
Business Education & Pearson Correl. & $.748^{* *}$ & $.739^{* *}$ \\
& Sig. & 0 & 0 \\
\hline & & \multicolumn{2}{c}{ Source: Authors' own research. }
\end{tabular}


The PROCESS macro for SPSS version 3.5 was used to investigate the mediation model and the associated roles of the variables (Iacobucci, 2008; Hayes, 2012). The academic management (AM) serves as a predictor, KM serves as a mediator, and BE serves as an outcome variable in the mediation process. The analysis demonstrates that a variation in the predictor variable (AM) causes a change within the mediator $(\mathrm{KM})$, which causes a modification in the outcome variable (BE). The statistical findings of the mediation analysis indicate the essential indirect mediation effect through the relevant mediation of KM in the relationship between AM, and the outcome variable BE.

Table 5. Regression results for the PROCESS mediation

\begin{tabular}{lllllll}
\hline Model & Coeff. & SE & t & p & CI (lower) & CI (upper) \\
\hline Model without mediator & & & & & & \\
AM -> BED (c) & 0.9128 & 0.0568 & 16.077 & 0 & 0.8009 & 1.0248 \\
Model with mediator & & & & & & \\
AM -> KM (a) & 0.8527 & 0.0495 & 17.209 & 0 & 0.755 & 0.9504 \\
KM-> BED (b) & 0.5358 & 0.0822 & 6.517 & 0 & 0.3737 & 0.6979 \\
AM -> BED (c') & 0.4421 & 0.0742 & 5.9585 & 0 & 0.2958 & 0.5884 \\
\hline & & & & & \multicolumn{2}{c}{ Source: Authors' own research. }
\end{tabular}

Step 1: the regression of Academic management on Business education was significant for the mediation model, when the mediator was ignored. $\mathrm{F}(1,204)=258.49, \mathrm{p}<.001, \mathrm{R} 2=.55$, $\mathrm{b}=.91, \mathrm{t}(204)=16.07, \mathrm{p}<.001$.

Step 2: the regression of Academic Management (AM) on the mediator, Knowledge Management $(\mathrm{KM})$, was similarly significant, $\mathrm{F}(1,204)=296.17, \mathrm{p}<.001, \mathrm{R} 2=.59, \mathrm{~b}=.85, \mathrm{t}$ $(204)=17.20, \mathrm{p}<.001$.

Step 3: Academic Management's (AM) regression on the mediator, Knowledge Management $(\mathrm{KM})$, was also substantial, $\mathrm{F}(2,203)=168.85, \mathrm{R} 2=.62, \mathrm{p}<.001, \mathrm{~b}=.44, \mathrm{t}(203)=$ $5.95, \mathrm{p}<.001$.

Step 4: Academic Management (AM) scores were found to be a less significant predictor of Business Education (BE) after controlling for the mediator - Knowledge Management (KM), b $=.53, \mathrm{t}(203)=6.51, \mathrm{p}<.001$.

Table 6. Sobel test

\begin{tabular}{llll}
\hline Test & Test Statis tics & Standard Error & p-value \\
\hline Aroian test & 6.08 & 0.075 & 0 \\
Goodman test & 6.1 & 0.074 & 0 \\
\hline \multicolumn{2}{r}{} & & Source: Authors' own research.
\end{tabular}

The Aroian variant of the Sobel test was used to determine if Knowledge Management $(\mathrm{KM})$ mediated the relationship between $(\mathrm{AM})$ and $(\mathrm{BE})(\mathrm{z}=6.08, \mathrm{p}=.000)$, as proposed by Baron and Kenny (1986). In the same regard, after applying the Goodman version of the Sobel test $(\mathrm{z}=6.10, \mathrm{p}=.000)$, the same findings were found, showing a full mediation effect. 


\section{Conclusions}

The main purpose of the study was to determine the indirect effect between AM and BE through the proposed mediator KM and to which degree can explain the proposed causal relationship. This study has provided evidence that academic management (AM) has a direct effect on business education $(\mathrm{BE})$ due to the causality relationship between the variables.

The results highlight the fact that adaptive academic management processes (AM) undertaken by expanding the learning and teaching actions to the business environment will have an impact in the business education outcome. Results of the PROCESS mediation confirm that Business Education (BE) is significant influenced by Academic Management (AM) through a causal sequence in which the degree of changes arisen in (AM) will influence changes in the mediator $(\mathrm{KM})$ which in turn influences $(\mathrm{BE})$.

The mediation effect was confirmed showing the significant influence that (AM) both directly and through the mediation effect of (KM) has on (BE) and business knowledge. Nowadays higher education and higher education management processes are in the business knowledge, as several core activities are associated with knowledge creation, dissemination, and learning of competencies and skills required on the labor market. This relationship is a strong indicator that business knowledge and business competencies are relevant values for career development and higher employability

\section{References}

Andriessen, D. (2004). Making sense of intellectual capital: designing a method for the valuation of intangibles. Amsterdam: Elsevier.

Baron, R.M., \& Kenny, D.A. (1986). The moderator-mediator variable distinction in social psychological research: conceptual, strategic, and statistical considerations. Journal of Personality and Social Psychology, 51(6), 1173-1182.

Bass, B.M., \& Riggio, R.E. (2006). Transformational leadership. $2^{\text {nd }}$ Edition. London: Lawrence Erlbaum Associates, Publishers.

Bejinaru, R. (2018). Assessing students' entrepreneurial skills needed in the knowledge economy. Management \& Marketing. Challenges for the Knowledge Society, 13(3), 1119-1132.

Bereiter, C. (2009). Education and mind in the knowledge age. New York, NY: Routledge.

Bonett, D., \& Wright, T. (2014). Cronbach's alpha reliability: interval estimation, hypothesis testing, and sample size planning. Journal of Organizational Behavior; DOI: 10.1002/ job. 1960 .

Bratianu, C. (2014). Intellectual capital of the European universities. In Dima, A.M. (Ed.). Handbook of research trends in European higher education convergence, 24-43. Hershey, NY: IGI Global.

Bratianu, C. (2020). Toward understanding the complexity of the COVID-19 crisis: a grounded theory approach. Management \& Marketing. Challenges for the Knowledge Society, 15, Special Issue (SI1), 410-423. DOI: 10.2478/mmcks-2020-0024.

Bratianu, C., \& Bejinaru, R. (2020). Knowledge dynamics: a thermodynamics approach. Kybernetes, 49(1), 6-21. DOI: 10.1108/K-02-2019-0122.

Bratianu, C., Hadad, S., \& Bejinaru, R. (2020). Paradigm shift in business education: a competence-based approach. Sustainability, 12, 1348. DOI: 10.3390/su12041348. 
Bratianu, C., \& Pinzaru, F. (2015). University governance as a strategic driving force. In Dias, J.C. (Ed.). Proceedings of the $11^{\text {th }}$ European Conference on Management, Leadership, and Governance, Military Academy, Lisbon, Portugal, 12-13 November 2015, pp. 28-35. Reading: Academic Conferences and Publishing International.

Bratianu, C., \& Vasilache, S. (2009). Evaluating linear-nonlinear thinking style for knowledge management education. Management \& Marketing, 4(3), 3-18.

Bratianu, C., \& Vatamanescu, E.M. (2017). Students' perception in developing generic skills for business: a knowledge approach. VINE Journal of Information and Knowledge Management Systems, 47(4), 490-505. DOI: 10.1108/VJKMS-11-2016-0065.

Chen, L., \& Mohamed, S. (2008). Impact of the internal business environment on knowledge management within construction organizations. Construction Innovation, 8(1), 61-81.

Daft, R.L. (2008). The leadership experience. $4^{\text {th }}$ Edition. Mason, OH: Thomson Higher Education.

Damasio, A. (2012). Self comes to mind: constructing the conscious brain. New York, NY: Vintage Books.

Drucker, P.F. (2008). The age of discontinuity: Guidelines to our changing society. New Brunswick, NY: Transaction Publishers.

Eizaguirre, A., Garcia-Feijoo, M., \& Laka, J.P. (2019). Defining sustainability core competences in business and management studies based on multinational stakeholders' perceptions. Sustainability, 11, 2303. DOI: 10.3390/su11082303.

Friedenberg, J., \& Silverman, G. (2016). Cognitive science: an introduction to the study of mind. $3^{\text {rd }}$ Edition. Los Angeles: SAGE Publications.

Garcia-Perez, A., Cegarra-Navarro, J.G., Bedford, D., Thomas, M. \& Wakabayashi, S. (2020). Critical capabilities and competencies for knowledge organizations. Bingley: Emerald Publishing.

Gherardi, S., Nicolini, D., \& Odella, F. (1998). Toward a social understanding of how people learn in organizations: the notion of situated curriculum. Management Learning, 29(3), 273-297.

Hayes, A. (2012). PROCESS: A versatile computational tool for observed variable mediation, moderation, and conditional pro-cess modeling [White paper], Retrieved from http:// www.afhayes.com/public/process2012.pdf.

Horney, N., Pasmore, B., \& O'Shea, T. (2010). Leadership agility: a business imperative for a VUCA world. People and strategy, 33(4), 33-38.

Iacobucci, D. (2008). Mediation analysis. Thousand Oaks, CA: SAGE Publishing.

Kahneman, D. (2011). Thinking, fast and slow. New York, NY: Farrar, Strauss and Giroux.

Kolb, D.A. (2015). Experiential learning: experience as the source of learning and development. $2^{\text {nd }}$ Edition. Upper Saddle River, NJ: Pearson Education.

Lafayette, B., Curtis, W., Bedford, D., \& Iyer, S. (2019). Knowledge economies and knowledge work. Bingley: Emerald Publishing.

Le Deist, F.D., \& Winterton, J. (2005). What is competence? Human Resource Development International, 8(1), 27-46.

Lozano, R., Merrill, M.Y., Sammalisto, K., Ceulemans, K., \& Lozano, F.J. (2017). Connecting competences and pedagogical approaches for sustainable development in higher education: a literature review and framework proposal. Sustainability, 9, 1889, 1-15. DOI: $10.3390 /$ su9101889.

DOI: 10.2478/picbe-2021-0010, pp. 102-112, ISSN 2558-9652 |

Proceedings of the $15^{\text {th }}$ International Conference on Business Excellence 2021 
OECD (2005). The definition and selection of the key competences: executive summary. Paris: Directorate for Education and Skills.

OECD (2018). The future of education and skills: education 2030. Paris: Directorate for Education and Skills.

Martin, R. (2009). The design of business: Why design thinking is the next competitive advantage. Boston, MA: Harvard Business Press.

Mintzberg, H. (2004). Managers not MBAs: A hard look at the soft practice of managing and management development. Harlow: Pearson education.

Mocanu, R. (2020). The expanding role of customer knowledge management and brand experience during the pandemic crisis. Management Dynamics in the Knowledge Economy, 8(4), 357-369. DOI: 10.2478/mdke-2020-0023.

Preacher, K., \& Hayes, A. (2004.) SPSS and SAS procedures for estimating indirect effects in simple mediation models. Behavior Research Methods, Instruments, and Computers, 36(4), 717-731.

Ricceri, F. (2008). Intellectual capital and knowledge management: strategic management of knowledge resources. London: Routledge.

Shatock, M. (2006). Managing good governance in higher education. Berkshire: Open University Press.

Surico, P., \& Galeatti, A. (2020). The economics of a pandemic: the case of COVID-19. London: London School of Economics.

Taleb, N.N. (2012). Antifragile: how to live in a world we don't understand. London: Penguin Books.

Tsang, H.W.V., \& Tsui, E. (2017). Conceptual design and empirical study of a personal learning environment and network (PLE\&N) to support peer-based social and lifelong learning. VINE Journal of Information and Knowledge Management System, 47, 228-249.

Tsui, E., \& Dragicevic, N. (2018). Using the scenario development and personal learning environment and network to support curriculum design. Management \& Marketing. Challenges for the Knowledge Society (2018). 13(2), 848-858. DOI: 10.2478/mmcks2018-0009.

Zakaria, F. (2020). Ten lessons for a post-pandemic world. New York, NY: W.W. Norton. 